\title{
Price and Freshness Competition in RS Fresh Product Supply Chain Structure
}

\author{
Lu Cai* \\ East China University of Science and Technology \\ Shanghai,China \\ Yueluo_cl@163.com
}

Lin $\mathrm{Li}$

East China University of Science and Technology

\author{
Tijun Fan \\ East China University of Science and Technology \\ Shanghai,China \\ tjfan@ecust.edu.cn \\ Shanghai,China \\ e-mail: name@xyz.com
}

\begin{abstract}
This paper focuses on the fresh product supply chain consisting of two competing suppliers and one single retailer. The model accounts for product competition between the two kinds of products provided by two suppliers, as well as for freshness competition between them. We use a game-theoretic model to examine the RS leadership structure. Our results suggest that to be more successful and reap higher profits suppliers should pursue more substitute products with higher freshness and quantity efficient.
\end{abstract}

Keywords- Fresh product; Product differentiation; Freshness differentiation; Freshness; Quantity Effectiveness

\section{INTRODUCTION}

Fresh product is the basic consumer goods in daily life, and has become the indispensable nutrient source in people's diet composition. With the eating habits changed and awareness towards food freshness increased, food supply chain management is more challenged than ever. However, fresh product doesn't keep long as to the weak supply chain system of fresh products. According to a recent Accenture report, only $15 \%$ of all perishable products in China are transported in refrigerated vehicles (compared with nearly $90 \%$ in developed countries), resulting in a loss of $\$ 8.9$ billion annually in fruit and vegetable distribution. The channel selection decision for fresh product supply chain members is increasing important.

A lot of reports on this subject and relevant studies have been published. Blackburn and Scudder(2009) developed supply chain strategies for perishable productfresh produce. Blackurn and Scudder(2009) studied the supply chain strategies for perishable products. Cai(2010) considered both the obsolescence and deterioration of the fresh product during the process of transportation, and established a model to address the pricing and ordering decisions different from the traditional ones as to the freshness-keeping effort. $\mathrm{Li}(2014)$ also considered fresh agricultural product's wastage from quantity and quality and developed a two-stage fresh agricultural product supply chain revenue models with and without RFID technology. Widodo constructs a basic model of agricultural fresh products by formulating the plant growing process and the loss process of fresh products in mathematical forms to maximize a level of demand satisfied constantly in every period. Although these studies focused on fresh product supply chain management, no one has yet conducted a study about the competition between the different fresh product suppliers.

Therefore, this paper selecting fresh product supply chain as the research object, studies price competition and freshness competition in a channel structure with a common retailer. In the following section, we develop a model that examines price and freshness competition between two substitutable products in a channel structure with two suppliers and one retailer. In the third section, we derive the analytical solutions for the prices, margins, quantities and profits under different channel leadership structures. In the fourth section, we study the main outcomes and discuss the implications of different channel leaderships by conducting some sensitivity analysis and comparing results across different scenarios. Finally, in the last section, we conclude and delineate further research directions.

\section{THE MODEL}

We consider the RS leadership structure, in the RS case, the suppliers are the followers and the retailer is leader. This means that both the two competing suppliers and the retailer simultaneously choose the wholesale prices and the retailer's margins, respectively, for the two different fresh products. Fig.1 illustrates the channel leadership structure. Our main consist of (a) applying all these assumptions to a model including competition between the two different fresh products.

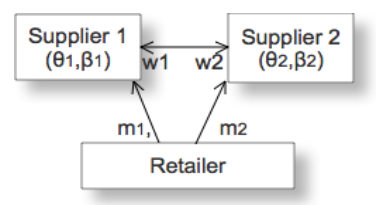

Figure 1. The RS channel leadership structure

We model the demand faced by the channel members as a linear function of retailer price $p_{i}$ and the level of freshness $\theta_{i}$. Further, let $w_{i}$ denote the suppliers' 
wholesale prices, $m_{i}$ the retailer's margin on the two substitutable products and $c_{m}$ the suppliers' cost of its product, and $\beta_{i}$ be the efficient of the product i. We consider retail price is considered to be the sum of the wholesale price and retail margin decisions (Choi, 1991).

Following the established literature, we use linear demand functions that capture the main properties: demanded quantity of a product decreases as its price increase or, as the competing product's price decreases, it also decreases as its freshness decreases and the competing product's freshness increases. Accordingly, we extend the demand function used in Choi et al.(1991) as follows (Zugang Liu 2012):

$$
q_{i}=a-p_{i}+k\left(p_{j}-p_{i}\right)+b\left(\theta_{i}-k\left(\theta_{j}-\theta_{i}\right)\right), i, j=1,2, j \neq i
$$

the profit function for each supplier can be written as :

$\pi_{S_{i}}=\left(w_{i}-\frac{1}{\beta_{i}} c_{m}\right) q_{i}, \quad i=1,2$

and the profit function for the retailer $\mathrm{R}$ :

$\pi_{R}=\sum_{i=1}^{2} m_{i} q_{i}$

where $m_{i}=p_{i}-w_{i}$ is the margin on the fresh product for the retailer $\mathrm{R}$.

\section{THE EQUILIBRIUM OUTCOMES}

This game is solved backwards. The suppliers first solve for the wholesale prices that maximize their profits simultaneously. The resulting reaction functions are used by the retailer while maximizing his own profit.

Solving for the suppliers' optimization problems, we get these reaction functions:

$$
\begin{aligned}
& w_{i}=\frac{1}{(3 k+2)(k+2)}\left[-\left(k^{2}+4 k+2\right) m_{i}+k(k+1) m_{j}\right] \\
& +\frac{1}{(3 k+2)(k+2)}\left[b \theta_{i}\left(k^{2}+4 k+2\right)-b \theta_{j} k(k+1)\right] \\
& +\frac{1}{(3 k+2)(k+2)}\left[a(3 k+2)+(k+1) c_{m}\left(\frac{2(k+1)}{\beta_{i}}+\frac{k}{\beta_{j}}\right)\right] \\
& w_{j}=\frac{1}{(3 k+2)(k+2)}\left[-\left(k^{2}+4 k+2\right) m_{j}+k(k+1) m_{i}\right] \\
& +\frac{1}{(3 k+2)(k+2)}\left[b \theta_{j}\left(k^{2}+4 k+2\right)-b \theta_{i} k(k+1)\right] \\
& +\frac{1}{(3 k+2)(k+2)}\left[a(3 k+2)+(k+1) c_{m}\left(\frac{2(k+1)}{\beta_{j}}+\frac{k}{\beta_{i}}\right)\right]
\end{aligned}
$$

From above expressions, we notice that the wholesale price for a product is positively related to its own freshness and competitor's retail price, while negatively related to the retail price and competitor's freshness.

In the next step, the retailer maximizes her profit given the reaction function of the suppliers. This yields the following optimal margins:

$$
\begin{aligned}
& m_{i}^{R S^{*}}=\frac{1}{2}\left(a+b \theta_{i}-\frac{c_{m}}{\beta_{i}}\right) \\
& m_{j}^{R S^{*}}=\frac{1}{2}\left(a+b \theta_{j}-\frac{c_{m}}{\beta_{j}}\right)
\end{aligned}
$$

Finally, substituting these values into the suppliers' reaction functions solve for the optimal wholesale prices:

$$
\begin{aligned}
& w_{i}^{R S^{*}}=\frac{1}{2(3 k+2)(k+2)}\left[b \theta_{i}\left(k^{2}+4 k+2\right)-b \theta_{j}\left(k^{2}+k\right)\right] \\
& +\frac{1}{2(3 k+2)(k+2)}\left[a(3 k+2)+c_{m}\left(\frac{5 k^{2}+12 k+6}{\beta_{i}}+\frac{k^{2}+k}{\beta_{j}}\right)\right]
\end{aligned}
$$$$
w_{j}^{R S^{*}}=\frac{1}{2(3 k+2)(k+2)}\left[b \theta_{j}\left(k^{2}+4 k+2\right)-b \theta_{i}\left(k^{2}+k\right)\right]
$$$$
+\frac{1}{2(3 k+2)(k+2)}\left[a(3 k+2)+c_{m}\left(\frac{5 k^{2}+12 k+6}{\beta_{j}}+\frac{k^{2}+k}{\beta_{i}}\right)\right]
$$

The rest of equilibrium values of the quantities demanded and profits for each one of the channel members are then straightforward to derive.

$$
\begin{aligned}
& p_{i}^{R S *}=\frac{1}{2(3 k+2)(k+2)}\left[b \theta_{i}\left(4 k^{2}+12 k+6\right)-b \theta_{j}\left(k^{2}+k\right)\right] \\
& +\frac{1}{2(3 k+2)(k+2)}[a(3 k+2)(k+3)] \\
& +\frac{1}{2(3 k+2)(k+2)}\left[c_{m}(k+1)\left(\frac{2(k+1)}{\beta_{i}}+\frac{k}{\beta_{j}}\right)\right] \\
& p_{j}^{R S^{*}}=\frac{1}{2(3 k+2)(k+2)}\left[b \theta_{j}\left(4 k^{2}+12 k+6\right)-b \theta_{i}\left(k^{2}+k\right)\right] \\
& +\frac{1}{2(3 k+2)(k+2)}[a(3 k+2)(k+3)] \\
& +\frac{1}{2(3 k+2)(k+2)}\left[c_{m}(k+1)\left(\frac{2(k+1)}{\beta_{j}}+\frac{k}{\beta_{i}}\right)\right]
\end{aligned}
$$

The prices are the same with that in the SS case, while the wholesale prices are lower. Therefore, the leader gets a larger share of a fixed total channel profit no matter who he is.

$$
\begin{aligned}
& q_{i}^{R S^{*}}=\frac{k+1}{2(3 k+2)(k+2)}\left[b \theta_{i}\left(k^{2}+4 k+2\right)-b \theta_{j}\left(k^{2}+k\right)\right] \\
& +\frac{k+1}{2(3 k+2)(k+2)}\left[a(3 k+2)-c_{m}\left(\frac{k^{2}+4 k+2}{\beta_{i}}-\frac{k^{2}+k}{\beta_{j}}\right)\right] \\
& q_{j}^{R S^{*}}=\frac{k+1}{2(3 k+2)(k+2)}\left[b \theta_{j}\left(k^{2}+4 k+2\right)-b \theta_{i}\left(k^{2}+k\right)\right] \\
& \frac{k+1}{2(3 k+2)(k+2)}\left[a(3 k+2)-c_{m}\left(\frac{k^{2}+4 k+2}{\beta_{j}}-\frac{k^{2}+k}{\beta_{i}}\right)\right]
\end{aligned}
$$


Proposition 1. In the RS scenario, retailer can get higher margin on product as long as its supplier makes freshness keeping effort.

Proposition 1 tells why retailer always prefer to the product with higher freshness. Retailer can get larger margin on product only when its own supply makes freshness keeping effort. That is, the retail margins are irrelevant to the product substitutability, and only relevant to its own quality, positively related to its own freshness and negatively related to its own efficient.

Proposition 2. In the RS scenario, wholesale price and retailer price on one product are dependent on the freshness and quantity loss of two products.

a. Supplier will decrease wholesale price of his product if competitor makes effort to improve freshness and physical quantity deterioration, which will also result in the decrease of retail price of his product.

b. Supplier will increase wholesale price if the improvement of her own product's situation $f_{1}(\theta, \tilde{\theta}, \beta, \tilde{\beta})>\frac{c_{m}\left(5 k^{2}+12 k+6\right)}{b\left(k^{2}+4 k+2\right)} \cdot$ Retailer will increase the retail price of product if the improvement

satisfies $\quad f_{1}(\theta, \tilde{\theta}, \beta, \tilde{\beta})>\frac{c_{m}(k+1)^{2}}{b\left(2 k^{2}+6 k+3\right)}$

Where $(\theta, \beta)$ and $(\tilde{\theta}, \tilde{\beta})$ are the parameter of product before and after change respectively,

$$
f_{1}(\theta, \tilde{\theta}, \beta, \tilde{\beta})=\frac{\tilde{\theta}-\theta}{1 / \beta^{-} 1 / \tilde{\beta}} .
$$

Proposition 2(a) shows an intuitively appealing result: a lower wholesale price will be charged for one product as competing fresher product are provided by another supplier. Furthermore, it will result in higher retail margin and lower retail price on this product, which implies the increase of margin is less than the decrease of wholesale price. Proposition 2(b) shows the change of price on product when better situation could be kept. It is interesting that we find the conditions that result in the increase of price, which implies that improvement of product doesn't necessarily bring higher price. And the condition expression $\left(\frac{c_{m}\left(5 k^{2}+12 k+6\right)}{b\left(k^{2}+4 k+2\right)}\right)$ that makes the increase of wholesale price is larger than that $\left(\frac{c_{m}(k+1)^{2}}{b\left(2 k^{2}+6 k+3\right)}\right)$ makes the increase of retail price.

Proposition 3. The difference of demand quantity for two competing product

$$
\frac{(k+1)(2 k+1)}{2(3 k+2)}\left[b\left(\theta_{i}-\theta_{j}\right)-c_{m}\left(\frac{1}{\beta_{i}}-\frac{1}{\beta_{j}}\right)\right] \text {. Only the }
$$

fresher product $\mathrm{i}$ is ordered by retailer when difference expression $f_{2}\left(\theta_{i}, \theta_{j}, \beta_{i}, \beta_{j}\right)$ of $\left(\theta_{i}, \beta_{i}\right)$ for less fresh product and $\left(\theta_{j}, \beta_{j}\right)$ drop to the threshold of $\frac{k(k+1)}{k^{2}+4 k+2}$. That is, $f_{2}\left(\theta_{i}, \theta_{j}, \beta_{i}, \beta_{j}\right)=\frac{a+b \theta_{j}-c_{m} / \beta_{j}}{a+b \theta_{i}-c_{m} / \beta_{i}}<\frac{k(k+1)}{k^{2}+4 k+2}$.

In proposition3, it is obvious that retailer will offer substitutable fresh product to consumers only if the freshness gap between two competing products is no more than the threshold $\frac{k(k+1)}{k^{2}+4 k+2}$. The quantity difference for products quantity is largely dependent on the difference of freshness and quantity loss for products.

Without loss of generality, we assume produce $\mathrm{i}$ is the less fresh product. Table 1 presents the above results concerning relationship among pricing decisions, competition and the effect of product parameters.

\section{DISCUSSION}

In this section, we discuss several implications of the results derived in the previous section.

\section{A. Effects of Product Competition}

$$
\text { Knowing }
$$$$
\text { from }
$$$$
\text { previous }
$$

section, $\frac{\partial w_{i}}{\partial k}<0, \frac{\partial w_{j}}{\partial k}<0, \frac{\partial p_{i}}{\partial k}<0, \frac{\partial p_{j}}{\partial k}<0, m_{i}, m_{j}$ have nothing to do with $k$.

That is, as product substitutability is higher, the two kinds of fresh products are less differentiated, equilibrium retail prices are higher. These higher retail prices can be attributed to higher wholesale prices. That means, as products are more differentiated, the wholesale prices decrease and the retail margins keep constant. Thus, as the suppliers differentiate the products more from each other, they can enjoy more monopolistic competition and charge higher wholesale prices to the retailers. On the other hand, the retailer's best reaction is to pass the wholesale price increase to consumers. Consequently, his retail margins keep constant while the retail prices increase.

Proposition4. Wholesale prices decrease as products substitutability increases. On the other hand, retail margins keep constant. Overall, retail prices decrease when the competition between the two products are growing.

\section{B. Effects of Consumers' freshness awareness}

Porossition5. For product i, $\frac{\partial m_{i}}{\partial b}>0, \frac{\partial w_{i}}{\partial b}>0, \frac{\partial p_{i}}{\partial b}>0$, while for product $\mathrm{j}$, it's a different case, $\frac{\partial m_{j}}{\partial b}>0$, else are showed in table 2 .

That is, as consumers' willingness to pay higher prices for fresher products increases, the retail can get higher 
margins on both products. While whether the suppliers can benefit from it depends on the product's freshness and his competitor's product's freshness. For the Supplier i who provides fresher product as we assumed, he can always benefit from it, while for the Supplier $\mathrm{j}$ it's not always a

TABLE I. RELATIONSHIP AMONG PRICING DECISIONS AND FRESH PRODUCT QUALITY

\begin{tabular}{|c|c|c|c|c|c|c|c|c|}
\hline & $m_{i}$ & $w_{i}$ & $p_{i}$ & $q_{i}$ & $m_{j}$ & $w_{j}$ & $p_{j}$ & $q_{j}$ \\
\hline$m_{i} \uparrow$ & - & $\downarrow$ & $\uparrow$ & $\bar{\uparrow}$ & $\downarrow$ & $\uparrow$ & $\uparrow$ & $\downarrow$ \\
\hline \multirow{3}{*}{$\begin{array}{l}\left(\theta_{i}, \beta_{i}\right)^{*} \\
\uparrow\end{array}$} & \multirow{3}{*}{$\uparrow$} & if $\frac{\tilde{\theta}-\theta}{1 / \beta^{-1 / \tilde{\beta}}}>\frac{c_{m}\left(5 k^{2}+12 k+6\right)}{b\left(k^{2}+4 k+2\right)}, \uparrow$ & $\uparrow$ & $\uparrow$ & \multirow{3}{*}{-} & \multirow{3}{*}{$\downarrow$} & \multirow{3}{*}{$\downarrow$} & \multirow{3}{*}{$\downarrow$} \\
\hline & & if $\frac{c_{m}(k+1)^{2}}{b\left(2 k^{2}+612 k+3\right)}<\frac{\tilde{\theta}-\theta}{1 / \beta-1 / \tilde{\rho}}<\frac{c_{m}\left(5 k^{2}+12 k+6\right)}{b\left(k^{2}+4 k+2\right)}$ & $\downarrow$ & $\downarrow$ & & & & \\
\hline & & if $\frac{\tilde{\theta}-\theta}{1 / \beta-1 / \tilde{\beta}}<\frac{c_{m}(k+1)^{2}}{b\left(2 k^{2}+612 k+3\right)}, \downarrow$ & $\downarrow$ & $\downarrow$ & & & & \\
\hline
\end{tabular}

*The parameter of less fresh product and fresher product satisfies $\frac{a+b \theta_{j}-c_{m} / \beta_{j}}{a+b \theta_{i}-c_{m} / \beta_{i}}>\frac{k(k+1)}{k^{2}+4 k+2}$.

TABLE II. RELATIONSHIP AMONG PRICING DECISIONS, COMPETITION AND THE EFFECT OF PRODUCT PARAMETERS

\begin{tabular}{lcc}
\hline$\frac{\theta_{j}}{\theta_{i}}$ & $\frac{\partial w_{j}}{\partial b}$ & $\frac{\partial p_{j}}{\partial b}$ \\
\hline$\left(0, \frac{k^{2}+k}{4 k^{2}+12 k+6}\right)$ & $<0$ & $<0$ \\
$\left(\frac{k^{2}+k}{4 k^{2}+12 k+6}, \frac{k^{2}+k}{k^{2}+4 k+2}\right)$ & $<0$ & $>0$ \\
$\left(\frac{k^{2}+k}{k^{2}+4 k+2}, 1\right)$ & $>0$ & $>0$ \\
\hline
\end{tabular}


good thing. When the freshness difference is small, Supplier $\mathrm{j}$ will benefit from it due to the substitutability, which is also called "free-rider" phenomenon. As the gap winded, Supplier j will decrease his wholesale price as b increases, this is mainly because the substitutability would fade away and the competition between the two products would gradually show up.

\section{CONCLUSIONS}

In this paper, we explore the roles of the two suppliers and the common retailer and their decisions by examining the fresh product supply chain under the RS leadership structures. The contribution of this paper is, different from the conventional studies, this paper considers competition between fresh product suppliers who provide different freshness and quantity efficiency product.

Our results, however, are based upon simplistic assumptions about the demand function in the additive case. Thus, there are possible extensions to improve our models. Such as, let the demand function in the multiplicative case, the supply chain with many suppliers and many retailers can also be considered in the future. In addition, this paper does not consider the coordination problem of the supply chain under decentralized decision, and suppose that demand information is symmetric. The coordination problem of the supply chain with asymmetric information will be studied in the future.

\section{ACKNOWLEDGMENT}

This work was supported by National Natural Science Foundation of China, Research Fund No.71170182, $71431004,71202053$.

\section{REFERENCES}

[1] Cook, R.L. (1990), "Challenges and opportunities in the US fresh produce industry",Journal of Food Distribution Research, Vol. 21 No. 1 , pp. 67-74
[2] Cook, R.L. (1999), "An overview of key food industry drivers: implication for the fresh produce industry", Journal of Food Distribution, Vol. 30 No. 1, pp. 1-4.

[3] Reardon, T. and Barrett, C.B. (2000), "Agro-industrialization, globalization and international

[4] development: an overview of issues, patters, and determinants",Agricultural Economics, Vol. 23 No. 3, pp. 195-205.

[5] Bolton J M, Liu W B. Creating an effective china cold supply chain-Current status, challenges and implementation considerations, Accenture Report[J]. 2006.

[6] Blackburn J, Scudder G. Supply chain strategies for perishable products: the case of fresh produce[J]. Production and Operations Management, 2009, 18(2): 129-137.

[7] Blackburn J, Scudder G. Supply chain strategies for perishable products: the case of fresh produce[J]. Production and Operations Management, 2009, 18(2): 129-137.

[8] Cai X, Chen J, Xiao Y, et al. Optimization and coordination of fresh product supply chains with freshness - keeping effort[J]. Production and Operations Management, 2010, 19(3): 261-278.

[9] LI Lin, FAN Tijun. Research on decision-making of fresh agricultural product supply chain with RFID technology[J]. Systems Engineering-Theory \& Practice, 2014, 34(4): 836-844(in Chinese).

[10] Widodo K H, Nagasawa H, Morizawa K, et al. A periodical flowering-harvesting model for delivering agricultural fresh products[J]. European Journal of Operational Research, 2006, 170(1): 24-43.

[11] Choi S C. Price competition in a channel structure with a common retailer[J]. Marketing Science, 1991, 10(4): 271-296.

[12] Liu Z L, Anderson T D, Cruz J M. Consumer environmental awareness and competition in two-stage supply chains[J]. European Journal of Operational Research, 2012, 218(3): 602-613. 